\title{
O surfe no cinema e a sociedade brasileira na transição dos anos 70/80
}

Victor Andrade de MELO* Rafael FORTES ${ }^{* *}$
*Escola de Educação

Física e Desportos, Universidade Federal do Rio de Janeiro.

**Universidade Federal

Fluminense.

\section{Resumo}

$\mathrm{Na}$ transição dos anos 70 para os anos 80 foram lançados quatro longas-metragens nos quais o surfe esteve centralmente presente, todos atraindo grande público: Nas ondas do surf, de Lívio Bruni Júnior (1978); Nos embalos de Ipanema (1978), Menino do Rio (1981) e Garota dourada (1983), os três de Antônio Calmon. Além disso, como coadjuvante, este esporte esteve ainda representado em outras películas do período. 0 que teria impulsionado o aumento da presença do surfe na produção cinematográfica brasileira? Como isso pode nos ajudar a pensar não só nas diferentes configurações do campo esportivo como também no contexto sociocultural do pais à época? Tendo em vista tais questões, esse artigo tem por objetivo analisar as quatro películas nas quais o surfe ocupou espaço privilegiado, produzidas no Brasil entre os anos de 1978 e 1983. Concluimos que os filmes analisados sinalizaram e contribuíram no forjar de novas dimensões simbólicas para a sociedade brasileira na transição dos anos 70/80, na qual o surfe passou a ser uma presença mais constante em vários espaços.

UnITERMOS: História do esporte; Sociologia do esporte; Juventude.

\section{Introdução}

Silvinha, Carol e Melissa, três amigas adolescentes que estudam no Colégio São Jorge, uma escola de classe média, conversam sobre seus sonhos. $\mathrm{O}$ diálogo se passa no quarto de Melissa. Carol, recém-chegada do exílio com os pais, sonha em ser diretora de cinema e filma o bate-papo com uma câmera super 8. Perguntada sobre o futuro, a anfitriã sorri e diz que quer se casar com o "menino do Rio". Enquanto fala, volta-se para a parede, onde se vislumbra um pôster do filme de mesmo nome.

A cena narrada é de Podecrer!, filme de Arthur Fontes que esteve em cartaz nos cinemas brasileiros nos últimos meses de 2007. A trama se passa na cidade do Rio de Janeiro, no ano de 1981, o mesmo de lançamento de Menino do Rio, de Antônio Calmon. A caracterização do lugar e da época apresenta o surfe e a praia como referências para as personagens principais, tanto as femininas, que frequentam constantemente o espaço, quanto as masculinas: Tavico, João, PP e Marquinhos são praticantes do esporte.
De fato, entre o fim dos anos 70 e o início dos 80 , o surfe, que se estruturava definitivamente no Brasil, um processo que tivera início na década de $50^{1}$, ocupou espaço de destaque em alguns longasmetragens. Anteriormente, a prática somente estivera presente em Garota de Ipanema (1967), um filme de Leon Hirszman, que tivera como roteiristas o próprio Leon, Vinícius de Moraes, Glauber Rocha e Eduardo Coutinho. A película traçava um perfil da classe média da Zona Sul do Rio de Janeiro nos anos 60 , sendo uma tentativa de desmistificar a ideia de "juventude dourada carioca".

$\mathrm{Na}$ trama, Márcia (interpretada por Márcia Rodrigues), a protagonista, tem um namoro com o campeão de surfe Pedro Paulo (Arduíno Colassanti) ${ }^{2}$. Naquele momento, a referência a este esporte já dialogava com a configuração de uma cultura juvenil de classe média, algo que não surpreende se considerarmos na película a presença e influência da bossa nova, um produto musical que dialogava claramente com o gosto deste estrato da populaçãa ${ }^{3}$. 
Depois de mais de 10 anos sem aparecer nos longas e curtas produzidos no Brasil ${ }^{4}$, naquela transição das décadas de 70 e 80 foram lançados quatro filmes onde o surfe esteve centralmente presente: Nas ondas do surf, de Lívio Bruni Júnior (1978)'; Nos embalos de Ipanema (1978), Menino do Rio (1981) e Garota dourada (1983), os três de Antônio Calmon.

Não foi nada desprezível a bilheteria dessas fitas, mesmo para os padróes do cinema nacional da época, superiores aos atuais. Segundo Ramos (1995), Menino do Rio foi assistido por mais de dois milhōes de pessoas, Nos embalos de Ipanema por mais de 500.000 mil espectadores, e Garota dourada, por mais de 600.000. Segundo BuENO (2005), Nas ondas do surf foi a segunda maior bilheteria de 1978 .

Além disso, como coadjuvante, o surfe também esteve presente em outras películas no decorrer da década de 80: como exemplo, Vai Vem à Brasileira, de Manuel Carlos Semião da Silva (1983); Fulaninha, de David Neves (1986); A menina do lado, de Alberto Salvá (1987) ${ }^{6}$.

O que teria impulsionado o aumento da presença do surfe na produção cinematográfica brasileira? Como isso pode nos ajudar a pensar não só nas diferentes configurações do campo esportivo como também no contexto sociocultural do país à época? Tendo em vista tais questôes, este artigo tem por objetivo analisar as quatro películas nas quais o surfe

\section{Configurações do surfe}

Um importante aspecto a ser inicialmente considerado é a ideia de contracultura. Fenômeno do fim dos anos 60 e início dos 70 , forjada em um contexto social, político e econômico complexo e específico, angariou adeptos e impulsionou arranjos e práticas diversas em distintos países, sempre dialogando com as peculiaridades locais.

Apesar dessas especificidades, é possível elencar alguns traços gerais: a acentuada recusa dos valores $\mathrm{da}$ geração anterior; a presença de jovens de classe média, sobretudo estudantes universitários, entre os principais agentes; a contestação e a reivindicação de mudanças para superar o capitalismo e a tecnocracia; a aproximação com o misticismo e com visões mágicas de povos que privilegiam a integração e a união (e não a conquista) da natureza; o uso de drogas com sentido de autoconhecimento e auto-percepção (Воотн, 2001; Clarke, 1976; RoszaK, 1972).

Para alguns, alinhar-se com a ideia de contracultura significava sair de casa e recusar valores estáveis ocupou espaço privilegiado, produzidas no Brasil entre os anos de 1978 e 1983.

Estamos seguindo a trilha de outros pesquisadores que já argumentaram que são férteis e constantes as relações entre cinema e esporte no decorrer da história (MARAÑON, 2005; Melo, 2006; Merida, 1995; Ramió, 2003). Fenômenos típicos da modernidade (ainda que possuam raízes anteriores), se organizando a partir das mudanças culturais, sociais e econômicas observáveis desde o fim do século XVIII e no decorrer do século XIX, ambos constituem-se como poderosas representaçóes de valores edesejos que permeiam o imaginário do séculoXX. Ambos celebraram e foram celebrados pelas novas dimensōes de vida e de sociedade construídas no decorrer do século que passou (MELO, 2006).

Seus diálogos constituem-se, portanto, em potenciais fontes para que possamos melhor compreender determinadas representações, sendo úteis para ampliar o nosso entendimento tanto sobre a prática esportiva quanto sobre a sociedade retratada.

Introdutoriamente apresentaremos alguns aspectos relativos à conformação do campo construído ao redor do surfe, buscando coletar elementos que nos ajudem a compreender a presença deste esporte no cinema brasileiro no período estudado. Posteriormente retomaremos algumas dessas discussões, quando nos debruçarmos mais especificamente sobre os filmes a serem analisados. tradicionais. Essa defesa de uma "vida nômade e libertária” se articula plenamente com uma certa representação da prática do surfe, algo bastante presente em muitos dos filmes nos quais tal esporte esteve inserido, relacionado a ideias como as de desapego dos bens materiais, de opção por uma vida simples junto à natureza e de realização de viagens com os amigos (CARMO, 2001; RosZAK, 1972).

Tais ideais, todavia, nunca foram consensuais. Em um dos centros da contracultura, a Califórnia, se gestou "uma nova cultura hedonista" do surfe, que "rapidamente se difundiu pelo anel do Pacífico, inicialmente através de um gênero hollywoodiano de filmes de praia" (Bоотн, 2001, p.91) ${ }^{7}$. Este autor afirma que a "cultura do surfe" e a mídia estão associadas desde o princípio, uma relação que se tornou clara e tem como marco uma película específica, um grande sucesso à época: "produtores de Hollywood identificaram cedo o potencial comercial da nova cultura e a Columbia Pictures lançou o gênero hollywoodiano em 1959 com Gidget", 
uma adaptação do livro homônimo de Frederick Kohner (BоOTH, 2001, p.91).

Defato, vários filmes que tinham como cenário a praia, tendo o surfe como destaque, foram realizados na primeira metade da década de $60^{8}$. Segundo Bоотн (2001, p.93), "as histórias de praia de Hollywood eram aventuras musicais e ajudaram a popularizar um estilo específico, a surf music". Música e cinema, tendo o surfe como tema, estavam associados e geraram grandes sucessos comerciais.

A articulação mídia-surfe, obviamente, trouxe para o esporte as ideias de lucro e exploração comercial, via mercado de entretenimento. Isso incomodou uma parte dos praticantes, desencadeando tensões na configuração do campo em construção. Muitos surfistas reclamavam da imagem pasteurizada divulgada por Hollywood e passaram a realizar suas próprias produçōes: inicialmente com características mais artesanais, logo se tornaram mais "profissionais", inclusive por ser uma possibilidade de trabalho para os que desejavam se dedicar integralmente ao esporte.

Estabeleceram-se, assim, dois tipos de filmes de surfe: os hollywoodianos (cujo foco era a "vida praiana") e os especializados (centrados na "camaradagem" do surfari, imagens de ondas grandes e perfeitas, valorização de locais exóticos e "secretos" e dos elementos mais intrínsecos à prática, como o "design" das pranchas e a excelência das manobras). Vejamos como, nesse sentido, o cinema se transformou não só em um importante fator de divulgação como também em um dos espaços em que se travavam disputas pelas representaçôes em torno do esporte, cujos valores eram bastante distintos:

Diferentemente do gênero hollywoodiano que retratava o surfe como um passatempo conformista, os homens e mulheres jovens nos filmes de surfe especializados, que desciam ondas e viajavam incessantemente, e que nunca trabalhavam ou se preocupavam, carregavam a mensagem potencialmente subversiva de que surfistas eram menos previsíveis, menos confiáveis e não tão prontos a se conformar (Воотн, 2001, p.95).

Os filmes especializados eram, assim, um canal para a divulgação da rebeldia e inconformismo característicos da cultura do surfe na Califórnia. As películas, exibidas fora dos grandes circuitos, eram recebidas com avidez pelos interessados: "ao fim da década, entusiastas e fãs se reuniam em clubes privados e salōes públicos para assistir a filmes especializados" (BоOTH, 2001, p.94). As audiências eram significativamente menores do que as dos longas hollywoodianos, pelo menos até o momento em que a própria ideia de rebeldia, em sentidos diversos, de alguma forma foi apreendida pelas películas do "mainstream".

Assim, os meios de comunicação exerceram papel central na expansão da visão hedonista do surfe para além da Califórnia, atingindo um público juvenil de diversos países e contribuindo para configurar estilos de vida. Devemos lembrar que a essa altura a cultura de massa já fornecia os "modelos dominantes" de referência aos adolescentes - ocupando o lugar que era anteriormente da família e da escola (Morin, 1997, p.157). Cinema, revistas, rádio, televisão (e futuramente a internet) integraram-se, cabendo à produção audiovisual sempre um lugar de destaque.

No Brasil, segundo Bueno (2005) e DiAs (2008), esse processo começa a se delinear já nos anos 60 , mas é mesmo no fim dos anos 70 que se torna mais claro, antecipando o "boom" dos anos 80. Esse é um momento marcado pela transição da ditadura para a democracia. Se por um lado eram perceptíveis importantes avanços, como a reestruturação do movimento estudantil e operário, a revogação do AI5 e a anistia e o retorno dos exilados, por outro os centros de tortura e os serviços de espionagem ainda não haviam sido desativados, as produções artísticas ainda estavam submetidas à censura e setores contrários à abertura jogavam suas fichas em atividades conspiratórias para forjar a necessidade de se manter a estrutura de repressão funcionando a pleno vapor. Ventos de liberdade começavam a soprar, mas nuvens negras ainda pairavam sobre os céus brasileiros: a produção cultural certamente expressava essas tensões.

No que diz respeito ao surfe, a estruturação e organização das competições e do profissionalismo ainda davam os primeiros passos: os campeonatos ainda eram esporádicos (ainda que torneios como os de Saquarema e do Arpoador já fossem reconhecidos) e a maior parte dos surfistas era amador; poucos contavam com patrocínios. O crescimento do número de praticantes, contudo, já era flagrante, algo claro inclusive na fundação de diversas associaçōes locais e estaduais, que buscavam organizar os atletas e melhor promover os circuitos.

A produção midiática sobre o surfe dá um salto no Brasil, um retrato do crescimento do interesse do público e do fato de que a juventude passava a ser cada vez mais um alvo do mercado e dos meios de comunicação, algo que certamente também está articulado com o clima de esperança e jovialidade que o fim da ditadura começa a propiciar. Além de nos já citados filmes, o esporte se faz presente em revistas, na rádio, na televisão. 
Fluir, a revista brasileira mais vendida e longeva dedicada ao esporte, é criada em 1983, dando sequência e aperfeiçoando algumas experiências anteriores, como a da pioneira Brasil Surf, criada em 1975. Em 1986 já havia no país oito publicações tendo o surfe como assunto central (MIRA, 2001). Emissoras de rádio, como a Maldita Fluminense FM - de Niterói, criada em 1982, voltada para o público jovem que ouvia "rock" - tiveram participação importante na divulgação dos campeonatos de surfe (MELLO, 1992). A fala de Ricardo BoCÃo ${ }^{10}$, por ocasião da comemoração de 20 anos da Fluir, reforça a ideia de havia uma articulação entre distintos elementos naqueles primeiros anos dos anos 80 :

Me lembro de três grandes explosões. A ditadura chegando ao fim, o rock nacional pipocando com os Titãs, Blitz, Legião Urbana, Paralamas do Sucesso, Barão Vermelho, Kid Abelha, Capital Inicial, Ultraje a Rigor e o surf brasileiro explodindo pela segunda vez (depois de 76, 77 e 78) (2003b).

Na televisão, em 1980, a novela Água Viva, de Gilberto Braga, exibida pela Rede Globo, trouxera a cultura de praia para o horário nobre, causando polêmicas pelas referências ao "topless" (uma nova moda nas areias cariocas) eà maconha. Na abertura, velas de windsurfe "bailavam" ao som da música Menino do Rio, de Caetano Veloso, na voz de Baby Consuelo: "o Havaí, seja aqui”. Em 1983, Realce, o primeiro programa de esportes de ação da televisão brasileira, estreia na Rede Record do Rio de Janeiro, apresentado por dois surfistas: Ricardo Bocão e Antonio Ricardo.

Os filmes de surfe chamaram a atenção para a temática e inspiraram uma narrativa que se materializou no seriado Armaçáo ilimitada (19851988), uma referência na história recente da televisão brasileira. O coordenador artístico e um dos roteiristas era Antônio Calmon, contratado pela Rede Globo "por saber falar ao público jovem", diretor de três das quatro películas nas quais o surfe ocupou, no período, importante espaço; um dos personagens centrais era interpretado por André de Biase, o mesmo protagonista daqueles filmes.

\section{Nas ondas do surf}

Se considerarmos que Nas ondas do surf ${ }^{11}$ (Lívio Bruno Junior, 1978) é o único documentário entre os quatro filmes por nós analisados, poderíamos a princípio pensar que trata-se de uma produção
O seriado caracterizava-se pela "inovação na linguagem" e "infinidade de referências à cultura pop", entre as quais "desenhos animados, cinema, programas de televisão, gibis, rock, surf, etc.” (RAMOs, 1995, p.77). Para MirA (2001), foi o produto midiático que colocou definitivamente o surfe na moda no país.

Para a consolidação dessas iniciativas, passou a ser necessário não apenas a formação de um público cativo, mas também atrair anunciantes que custeassem a produção. No caso das revistas, por exemplo, o preço de venda mal cobria os custos de impressão e distribuição. A Fluir, para viabilizar-se em seus primeiros momentos, cobria vários esportes (surfe, vôo livre, bicicross e skate) e tinha periodicidade bimestral. Após algumas edições, o crescimento do número de propagandas específicas de surfe (fabricantes de roupas, equipamentos e acessórios) é decisivo para a publicação excluir os demais esportes e se tornar mensal.

A juventude, mesmo a que não praticava o surfe e vivia longe das praias, usava roupas e acessórios de marcas como Pier, Company, Rico, K \& K, originais, compradas nas lojas, ou adquiridas nos camelôs que proliferaram pela cidade. Como bem identifica BuENo (2005, p.77):

Uma das mudanças mais significativas no tocante à produção cultural juvenil nos anos 80 , em relação às décadas anteriores, foi a sua abrangência. Se nos anos 50 e 60 essa produção concentrou-se entre os jovens da classe média urbana, a partir dos anos 70 os setores operários tiveram acesso mais direto às experiências e produtos juvenis. Isso ocorreu graças à incorporação dos jovens de baixa renda ao mercado de trabalho formal, possibilitando as transformaçóes dos padrôes de consumo.

Essa produção midiática, portanto, ao mesmo tempo em que divulgava o surfe e seu estilo de vida, é, em si, uma prova da consolidação de um mercado em torno deste esporte no Brasil, bem como da construção de novas referências simbólicas em nossa sociedade, onde se destaca a juventude como referência. Os filmes que analisaremos certamente nos apresentarão mais dados sobre esses aspectos.

absolutamente distinta das demais. Certamente é a que mais apropriadamente pode ser chamada de filme de surfe, próxima das características do tipo de película alternativa. $\mathrm{Na}$ verdade, ao tentar captar o clima 
existente ao redor do esporte que se estruturava, o longa exibe uma série de representaçôes que futuramente serão incorporadas nos filmes de ficção nos quais o surfe ocupa espaço importante (mais próximos do tipo "hollywoodiano").

Este é, aliás, o aspecto mais significativo de "Nas ondas do surf": difundir pioneiramente um estilo de vida que estava em construção, já delineando elementos-chave que sempre serão ressaltados ao redor dessa prática esportiva: a vida na natureza, o desejo de correr risco, o prazer de viajar, a beleza das praias e dos novos corpos "dourados".

Da mesma forma, o filme já traça um perfil do surfista como personagem controvertido, que tem problemas com a polícia e/ou com aqueles que não o compreendem em suas opçōes de vida, equivocadamente considerado por uns um desviante, por outros, um alienado. $\mathrm{Na}$ tentativa de desfazer essa visão, ao mesmo tempo a película demonstrava que existe um grande cadeia econômica sendo gestada ao redor da prática: a mensagem é que há "coisas sérias" por trás dessa aparente brincadeira.

O longa dialoga tanto com o contexto brasileiro, especificamente com o primeiro grande fluxo de desenvolvimento do esporte, quanto com as experiências documentais de filmes norte-americanos, que passaram na época a ser mais exibidos no Brasil, em circuito alternativo, normalmente procurado pelos já iniciados. A narrativa é muito semelhante às mais famosas fitas de surfe do momento: muitas cenas de atletas "pegando onda", espontaneamente ou em algum campeonato (no caso de Nas ondas do surf, a etapa do Primeiro Circuito Mundial, realizada na Praia do Arpoador, e o Festival Nacional de Saquarema, organizado na Praia de Itaúna, ambos em 1976); música instrumental de fundo (a trilha esteve sob a responsabilidade do grupo $A$ Cor do Som, que à época buscava uma sonoridade alternativa e que futuramente também embarcaria na onda pop); a exibição de imagens que buscam a valorização da integração homem-natureza e da sensação de emoção. Essas opções estéticas serão futuramente reproduzidas e muito comuns também nos programas de televisão.

As informações técnicas apresentadas, narradas por Sérgio Chapelin a partir de texto bastante didático de Alberto Pecegueiro, à época editor da pioneira Brasil Surf, reforçam a impressão de que a película intentava mesmo praticamente dar uma aula de surfe para o grande público.

O filme traz também algumas breves entrevistas com alguns dos principais surfistas da época (Ricardo Bocão, Otávio Pacheco, Daniel Friedman e Pepê), apresentados como indivíduos antenados com a natureza, amantes de um estilo de vida simples e despojado do aparato tecnológico da cidade. Vemos ainda cenas de skate e de vôo livre, apresentados como esportes desdobramentos do surfe ${ }^{12}$.

Lívio Bruni Junior, filho de um conhecido dono de cadeia de cinemas, já envolvido com outras produçōes cinematográficas, e Rossini Maranhão, o Maraca, um dos pioneiros do surfe carioca e um dos primeiros a ter surfado no Havaí, realizam, assim, um documentário que é resultado tanto de uma visão comercial quanto do desejo de contribuir para a difusão do esporte.

O filme apresenta claras deficiências do ponto de vista técnico e narrativo. De qualquer forma, esse aspecto "primitivo" tem grande relação com o próprio momento de desenvolvimento do surfe no Brasil. O depoimento de Ricardo BoCÃo (2005) nos permite saber mais sobre os bastidores das filmagens. Inicialmente, comenta a exibição das primeiras cenas, captadas no Rio de Janeiro:

Dois meses depois, o pessoal da revista Brasil Surf e os principais surfistas cariocas da época foram ver o material bruto numa das melhores salas de cinema da cidade, o Bruni Ipanema. Sentei na fileira onde estava o Lívio e quando as luzes se acenderam, ele perguntou se eu havia gostado e se aquilo não daria um filme. Ele já tinha até um nome - "Brasil no Surf". Eu respondi que o material estava alucinante, mas ponderei que um assunto só (o campeonato) não seguraria um longa metragem e deixaria o filme maçante. E que um filme de surf tinha que ter o Hawaii.

Assim, deslocou-se uma equipe de produção para o Havaí, para captar cenas dos brasileiros em ação e de um campeonato, no qual participavam alguns dos grandes surfistas mundiais da época (Mark Richards, Shaun Tomson, Michael Ho, Gerry Lopez, Ian Cairns e Peter Townend, entre outros).

Quanto às filmagens no Havaí, BoCÃo (2005) afirma que o esquema pouco profissional ocasionou diversos problemas:

No começo, o objetivo de fazer parte do filme surfando altas ondas era a única coisa que importava para todos. Depois de um mês, a convivência quase diária com pessoas bem diferentes entre si começou a cobrar a fatura, e o preço foi ficando um pouco mais alto. (...) Eu pensei: "Já estou nessa função há quase três meses e não ganhei nada por esse trabalho. Me comprometi na empolgação do momento e agora vou até o fim, mas quando acabar o último rolo, vou me mandar para as outras ilhas do arquipélago sozinho, sem falar nada para ninguém”. 
Parece curioso que essa fala venha de um dos pioneiros da presença do surfe na televisão brasileira, mas o esporte naquele momento ainda não se configurara plenamente como opção profissional: o romantismo não era só um discurso, mas uma concreta alternativa de vida. O próprio BoCÃo (2004a) lembra de como fora morar em Saquarema, conhecida como o "Maracanã do surfe":

Liguei para o Betão, meu grande amigo na época e falei: "Vamos morar em Saquarema, fazer uma oficina de pranchas e pegar altas ondas". Financeiramente, não havia muita pressão. Cobrávamos 1800 cruzeiros, numa prancha. O aluguel da pequena casa onde morávamos, no canto esquerdo de Itaúna, custava 500 cruzeiros. O da nossa oficina, no canto direito (Lagoinha), outros 500 cruzeiros. E trabalhando, éramos apenas três - os dois donos e uma terceira pessoa. Comida? Muito barata. Gasolina? Nos deslocávamos só de bicicleta para ir do canto esquerdo para o canto direito da praia e às vezes para a cidade. E a margem de lucro? Pode parecer exagero, mas era de $100 \%$. Ou seja, só precisávamos de duas encomendas por mês para a nossa sobrevivência. Uma prancha pagava o material das duas e a outra pagava os nossos custos pessoais e os da oficina. Vivíamos de maneira simples, com boa alimentação, muita fogueira e violão e quase nenhum gasto.

$\mathrm{Na}$ verdade, o surfista repetira uma experiência que já tivera quando vivera no Havaí, sempre a busca das melhores ondas:

Eu cobrava 65 dólares para laminar uma prancha até 8 pés. Pagava 10 para o lixador e uns 5 por uma quilha de madeira com fibra de vidro. Gastava uns 30 em material e o lucro de 20 dólares dava para duas semanas de supermercado. Comendo aveia cozida com banana de manhã, sanduíches de pão integral com verduras e algum tipo de queijo no almoço e jantando praticamente todas as noites arroz integral, lentilhas e legumes, 10 dólares semanais em 1974 eram suficientes. As ondas eram de graça (BoCÃo, 2004b).

Como esse tipo de vinculação, não surpreende a sua posição nostálgica, alguns anos depois:

Saudade. Éramos mais puros. Sob todos os aspectos. Pranchas sem cordinha e sem logotipos. Todos nadavam longas distâncias para pegá-las e ninguém reclamava da falta de patrocínio, nem do patrocinador, pois eles não existiam. Cada um se virava com criatividade ou esforço para conseguir viajar em busca de ondas melhores ou para participar daquele pioneiro, exótico e místico campeonato longe do seu país. A única recompensa era a alegria de surfar ondas que você só conhecia através de uma foto ou a realização pessoal de participar de campeonatos que tinham a sua história contada pelo bocaa-boca dos mais viajados (BoCÃO, 2006a).

A grande bilheteria de Nas ondas do surf, com todos os limites de sua realização, de alguma forma indica a já grande presença desse esporte entre a juventude e antecipa em alguns anos o espaço que ocupará no imaginário da população nos anos 80 . Antes, contudo, do sucesso dos filmes dessa década ainda tivemos nos 70 outro longa em que o surfe ocupou espaço de relevância: Nos embalos de Ipanema.

\section{Nos embalos de Ipanema}

No nosso modo de entender, Nos embalos de Ipanema (Antônio Calmon, 1978) ${ }^{13}$ não pode ser chamado efetivamente de um filme de surfe, embora flertasse, buscasse vinculação e desejasse atrair um público específico. Calmon, que já dirigira algumas pornochanchadas, parece ter realizado uma película híbrida, esteticamente no meio do caminho entre os anos 70 e anos 80 , já visualizando um possível público juvenil, mas ainda trazendo muitos elementos de suas experiências cinematográficas anteriores (vale lembrar que, ao contrário de seus próximos filmes, neste a censura foi de 18 anos).

O diretor, na verdade, sempre procurou ponderar seu envolvimento com o gênero:

é necessário fazer um segundo esclarecimento: é muito mais fácil simplesmente me colocar como um realizador de filmes pornô ou, sejamos diretos, de pornochanchadas, do que reconhecer a incapacidade de crítica diante do novo. As pornochanchadas sempre foram conformistas e meus filmes são corrosivos. As pornochanchadas são moralistas enquanto que meus filmes são totalmente amorais. As pornochanchadas odeiam o sexo e a mulher, duas das referências mais importantes do meu cinema. A pornochanchada, finalmente, é sintoma de um estágio primitivo da sexualidade, o que não é exatamente o meu caso. 
O fato de um autor se apropriar culturalmente de um fenômeno de massas não é a mesma coisa do que fabricar cegamente um produto para ganhar o mercado. Eu não conseguiria fazer uma pornochanchada "pura" mesmo que quisesse. Acredito que o artista, independente de um programa ou de justificativas intelectuais, sempre reflete em seu trabalho o próprio mundo interior e a interação deste mundo com a realidade social. Sei que faço um cinema agressivo e irreverente, que não me apoio na chamada respeitabilidade artística tão importante em nossa província cultural e que nem me guardo num vanguardismo que pode ser fascinante aqui, mas é ridículo nas matrizes de Nova York e Paris. Meus filmes são sujos e ásperos como o país e não uma transposição emaculada e "artística" da realidade ${ }^{14}$.

A despeito dessas ressalvas, parte de sua obra ficou mesmo relacionada ao gênero e não há como negar reflexos dele em Nos embalos de Ipanema, notadamente a articulação de uma forte carga de erotismo e comédia.

Não por acaso a relação entre surfe e Ipanema foi estabelecida no filme, algo que já fora referido em Garota de Ipanema, de Hirszman. Nos anos 50 e 60, naquele bairro vivia grande parte dos pioneiros surfistas cariocas e aquela praia era constante local da prática; o lendário Arpoador é praticamente uma continuação de Ipanema.

$\mathrm{Na}$ década de 70, a instalação de um píer para a construção de um emissário submarino acabou por proporcionar melhores condições para a formação de ondas. Além disso, as "dunas" formadas pela areia revolvida foram "ocupadas" por jovens e artistas, sendo referência inclusive no que se refere ao uso de drogas. A ideia de "desbunde" passava por aquelas areias e o surfe se situava nesse contexto. Nesse cenário, não surpreende que também no bairro tenha sido aberta a primeira loja especializada no esporte no Brasil, a Magno.

O filme narra a história de Toquinho, interpretado por André de Biase (na primeira de muitas parcerias com Calmon), "bon vivant" morador de Marechal Hermes, cujo maior sonho é ir para o Havaí, viver "pegando ondas", sem precisar trabalhar. Para alcançar esse sonho, à busca de vida fácil e de condiçôes financeiras para sair com Patrícia (Zaira Zambeli), filha de burgueses de Ipanema, que se chocam com seus costumes avançados, Toquinho estabelece uma relação homossexual com André (Paulo Villaça) e aceita fazer programas com mulheres mais velhas, tudo capitaneado por Das Bocas (Roberto Bonfim), típico cafetão. $\mathrm{O}$ retrato das praias é menos glamoroso e idealizado do que se costuma ver em filmes de surfe.

O uso de drogas é apresentado de forma bastante distante da ideia de alternativa no âmbito da contracultura. $\mathrm{O}$ surfista central é do subúrbio, vai à praia de trem e de ônibus, vive pedindo dinheiro para comer algo ou mesmo para voltar para casa. Sua prancha é velha; para comprar uma nova, não pensa duas vezes em se envolver em atitudes "moralmente condenadas". A distante Barra da Tijuca é apresentada não como um local bucólico, mas um bairro onde se localizam os motéis. Ao final, pelos depoimentos, tudo indica que Toquinho não se deu bem, o que faz com que todos neguem que o conheceram ou que com ele tiveram alguma forma de relação. Aliás, o próprio nome do personagem central é simbolicamente bem menos glamoroso do que o do protagonista do futuro Menino do Rio (Valente).

Nesta película, o surfe aparece como contraposição ao trabalho. Não se trata de um estilo de vida alternativo, mas de uma possibilidade para fugir da pobreza de opçóes que caracteriza o subúrbio, desde o ponto de vista do diretor, algo que será constantemente reforçado de forma estereotipada, notadamente na composição da mãe do surfista (interpretada por Yara Amaral) e de Verinha (Angelina Muniz), sua namorada de Marechal Hermes.

O surfe aparece somente como uma mediação/ desejo de identificação no âmbito dos choques entre os da Zona Norte e os da Zona Sul. Não surpreende que a mãe de Patrícia (Jacqueline Laurence) comente em determinado momento que, desde que construíram os túneis (Rebouças e Santa Bárbara), as praias passaram a estar "infestadas de suburbanos, farofeiros, paus de arara"; por isso sugere que se cobre a entrada no litoral. Mesmo Verinha, que não se deslumbra pela Zona Sul como Toquinho, acaba enganada por Maurício (Stepan Nercessian), seu patrão rico. Ao final, os dois personagens de Marechal Hermes, cada um a seu modo, parecem desiludidos acerca das possibilidades de serem respeitados nesse outro mundo dentro da mesma cidade.

Ainda que a construção do personagem surfista seja bastante estereotipada e mesmo preconceituosa, na fita vemos exibidas referências a uma cultura "surf", que só mais tarde se delineará melhor: revista do esporte, lojas especializadas, gírias, roupas. Em Menino do Rio e Garota dourada esse quadro estará mais claro. 


\section{Menino do Rio e a garota dourada}

Menino do Rio (Antônio Calmon, 1981) ${ }^{15}$ foi o primeiro filme brasileiro dos anos 80 dirigido ao público jovem. Na esteira do seu sucesso, dois anos depois é lançada uma continuação, Garota dourada (Antônio Calmon, 1983) ${ }^{16}$. Estava prevista ainda uma terceira parte, Menina Veneno, nunca realizada.

Nos dois longas, o personagem central é Valente (André de Biase), praticante de surfe e de vôo livre, membro de um grupo adepto a uma vida em que a simplicidade e o contato com a natureza são valorizados. Ao contrário de Toquinho, o surfista de Nos embalos de Ipanema, Valente é um herói sem ambiguidades morais. Deve-se ressaltar, contudo, que nos dois filmes da década de 80 não temos exatamente vilōes. Além disso, esse novo herói não está mais tão preocupado com os desígnios sociais, mas sim mergulhado em suas próprias questões.

Em Menino do Rio, a história da paixão de Valente por Patrícia (Cláudia Magno), frívola e ligada à alta sociedade, tem como pano de fundo alguns temas que compõe um belo panorama dos anos 80 . Não é equivocado afirmar que o filme capta, reforça e mesmo antecipa algumas das novas dimensōes que vão marcar a sociedade brasileira daquela década.

A película reflete um certo fastio com o clima opressivo dos anos 70, fruto tanto da situação de exceção política quanto do quadro econômico observável desde os anos 50: a aceleração do processo de industrialização ocasionou o rápido crescimento das cidades e a difusão dos novos produtos tecnológicos; como contraponto desencadeia-se um movimento de valorização do ambiente natural, um dos grandes componentes que estimularam o crescimento e estruturação dos esportes na natureza. Como afirmam Melo e Dias (2007, p.8):

O surgimento e/ou consolidação de hábitos de lazer estão diretamente relacionados aos "efeitos mentais" desencadeados pela nova organização das metrópoles. $\mathrm{Na}$ medida em que as taxas demográficas vão aumentando, a euforia inicial vai dando lugar à condenação desse ambiente urbanizado. As cidades passam a ser retratadas como "um pesadelo de multidōes", dotadas de um "cotidiano cercado de tormentos". A vida urbana passa a ser avaliada como insalubre, infectada, comprometida pelo ar sujo e poluído. (...) Nesse contexto, vemos crescer as preocupações com os "cuidados com o corpo e com a alma", popularizava-se ainda mais o exercício físico como forma de ocupação do tempo livre. A necessidade e o desejo de "desempenar os corpos" passam a ser mais comumente notados. (...) Cresce também a valorização da idéia de natureza. $\mathrm{O}$ sol, o mar e a montanha passam a ser cada vez mais adorados. Esse "culto" era também perceptível no surgimento de novos modismos, como o da jardinagem como hobby, da valorização de restaurantes de comida natural/macrobiótica e da popularização de certas práticas realizadas em contato com o ambiente natural. (...) Os esportes desenvolvidos em contato com a natureza se popularizam. $\mathrm{O}$ surfe, que em menos de uma década se disseminou entre jovens de classe média da Zona Sul do Rio de Janeiro, é um exemplo claro.

Menino do Rio dialoga claramente com o já discutido processo de desenvolvimento dos esportes de natureza, com referências à influência californiana. As citaçōes ao surfe já podem ser perceptíveis na logomarca da película, muito veiculada no enorme esquema de marketing que cercou seu lançamento e divulgação. Não surpreende também que a música central seja $D e$ repente Califórnia, de Lulu Santos e Nélson Motta: "Garota eu vou pra Califórnia, viver a vida sobre as ondas, vou ser artista de cinema, o meu destino é ser star. (...) $\mathrm{Na}$ Califórnia é diferente irmão, é muito mais do que um sonho".

$\mathrm{O}$ estilo despojado que marca os personagens centrais parece ser uma releitura local de uma cultura de praia, que tem no Havaí (e em seus símbolos, como os trajes estampados, os luaus, a alimentação) tanto uma referência quanto uma perspectiva, um ideal: esse é o desejo central de Valente, para lá viajar, junto com seu amigo Paulinho (Evandro Mesquita), que lá já vivera como esportista e mergulhador profissional. Este foi o sonho e um ritual de passagem para muitos surfistas brasileiros da época e mesmo dos dias de hoje.

Claramente empenhado na configuração de uma cultura juvenil, não surpreende que o filme dialogue com a conformação de uma cultura pop, algo claro inclusive na escolha dos músicos envolvidos com a produção (onde se destacam os nomes de Nélson Motta $^{17}$ e Lulu Santos), precursores dessa proposta nos anos iniciais de 1980. O processo de distensão política e um certo ar de maior liberdade que voltava a soprar, impulsionava as possibilidades de produção cultural no âmbito de várias manifestaçōes artísticas, mais reconhecidamente na música, com a gestação da conhecida geração BRock $^{18}$.

Há ainda um diálogo local, com a própria cidade do Rio de Janeiro, em si uma importante 
"personagem" da trama. Salta aos olhos a sua beleza natural, em pontos hoje praticamente irreconhecíveis em função do rápido processo de urbanização, notadamente da região da Barra da Tijuca e do Recreio dos Bandeirantes, onde não por acaso se passa grande parte da trama.

Como demonstra Cléber DiAs (2008), essa é uma região chave na construção de novos sentidos e significados para a cidade do Rio de Janeiro no período posterior à transferência da capital para Brasília, locus principal do desenvolvimento dos novos esportes relacionados à natureza. $\mathrm{O}$ filme, aliás, elege como locações espaços simbólicos do surfe carioca e nacional: Saquarema, onde foram realizados os primeiros festivais, a partir de 1975; São Conrado, mais marcado pela prática do vôo livre, e Arpoador, reconhecidamente a praia onde a cultura surf se consolidou no país, local, aliás, onde se instalou inicialmente o Circo Voador, casa fundamental para o surgimento e consolidação dos grupos musicais brasileiros nos anos 80 .

Não surpreende, assim, que o título faça referência à música de Caetano Veloso, que homenageava um carioca típico: a película enaltece um tipo ideal de "carioca Zona Sul", algo reforçado até mesmo pela escolha dos atores, gente que tem "a cara do Rio" (tais como Evandro Mesquita, Sérgio Mallandro, Cláudia Magno, além do próprio André de Biase, ainda que esse seja, na verdade, natural do Espírito Santo). Mesquita, Biase e Mallandro eram de fato surfistas amadores.

Em Menino do Rio, a narrativa e as opções estéticas ainda estavam distantes das atuais. As imagens dos corpos dos atores e atrizes, por exemplo, eram bastante distintas da atual exibição exuberante de músculos hipertrofiados e bem definidos; a própria forma de filmar de Calmon, calma e pausada, estava distante da lógica clip que marcaria as produçôes juvenis no decorrer dos anos $80^{19}$.

Nesse sentido, Garota dourada parece ocupar um espaço intermediário entre Menino do Rio e Armação ilimitada. Ainda que mantendo as tomadas lentas e pausadas, Calmon já busca um diálogo maior com os videoclipes, com os videogames, com as histórias em quadrinhos. A idéia de velocidade timidamente já se apresenta na inserção de ultraleves e da moto pilotada pela anjo Gabriel (interpretada pela cantora Marina), embora ainda prepondere o ideal de afastamento da cidade, de comunidade isolada à busca de prazer nas coisas simples da vida. Não surpreende que a nova heroína chame-se Diana (Bianca Byington), na mitologia romana a deusa dos animais e da caça.
Se em Menino do Rio, tratava-se de condições originais, que desencadeavam os conflitos da trama, em Garota dourada essas opçôes de vida são apresentadas como uma retomada, tanto para Valente, que fora abandonado, no início da trama, com sua filha, por Patrícia (Cláudia Magno), insatisfeita com o casamento que marcou o fim do primeiro filme, quanto para Zeca (Sérgio Mallandro), que agora astro do "rock" demonstra cansaço com a extensa agenda e com a perseguição das făs. Os dois praticamente fogem para Encantado, um lugar mágico no litoral de Santa Catarina.

Em ambas, o esporte, notadamente o surfe, compõe o quadro imagético e de representações, sendo central na configuração dos personagens e na constituição das dicotomias. Natureza, saúde, juventude, desafio, liberdade. Calmon, juntamente com Biase, ator símbolo dessas realizações, parecem ter captado bem as dimensões que marcavam o período.

Menino do Rio tem mesmo um ar de releitura da contracultura. Lá está a valorização da vida simples, do contato com a natureza (inclusive no que se refere à alimentação), do despojamento de bens materiais em excesso. Há a valorização da amizade, do companheirismo e fortes referências a uma cultura hippie, inclusive a símbolos orientais. Há insinuaçôes ao uso de maconha, certamente atenuadas porque uma das cenas fora cortada pela censura em função de, segundo o parecer, alguns personagens estarem fumando "um cigarro não convencional". O surfe aqui apresentado dialoga com essas representações, mesmo que seu processo de profissionalização já estivesse em curso ${ }^{20}$.

Há referências à liberdade sexual, explícita tanto nos comportamentos dos personagens centrais quanto em pequenas passagens, como, por exemplo, no fato de Ciça (representada por Nina de Pádua), amiga de Patrícia, aparecer lendo o "Relatório Hite sobre a Sexualidade Feminina", um "best seller" à época.

Em Garota dourada, outra discussão será alavancada ao redor da figura de Diana: a independência feminina. Se Patrícia, no início do filme, já demonstrara desprendimento ao deixar o marido e a filha para buscar a felicidade, comunicando sua escolha a Valente simplesmente com um bilhete, Diana desempenha o papel da fêmea que escolhe: diante de Valente e Betinho (Roberto Bataglin), é ela que decide com quem vai ficar. Vale lembrar que na mitologia romana, a deusa Diana valorizava sua virgindade e não se casara, mantendo-se sempre casta.

O conflito central, mais claro em Menino do Rio, é mesmo entre um estilo de vida tradicional, conservador e abastado, e outro jovem, livre e simples, do qual o 
surfe e os esportes de natureza fazem parte. Valente, mesmo tendo nascido no seio de uma família rica, abandona os negócios do pai para viver como surfista. Patrícia sente-se incomodada com a estrutura de sua família e abandona o "playboy" Adolfinho (interpretado por Ricardo Zambelli) para se envolver com Valente.

Ao fim, encerrando o filme, uma cena antológica: o casamento de Patrícia e Adolfinho, no tradicional Gávea Golf and Country Club, é interrompido por Valente, que chega de asa delta e leva a noiva consigo. A mesma Patrícia, ao final de Garota dourada, perderá Valente para Diana: paga por ter abandonado a família, a simplicidade e ambicionado pela volta ao seu antigo esquema de vida.

Nesse novo modelo de vida, o sonho de trabalho está ligado não mais à possibilidade de acúmulo de dinheiro ou aquisição de bens luxuosos, mas sim à oportunidade de viver sem se afastar de seu estilo. Em Menino do Rio, os personagens-centrais trabalham com fotografia de esportes (caso de Zeca), com atividades ligadas à natureza (caso de Paulinho) ou com a confecção de pranchas, caso de Valente, que inclusive ensina o ofício a Pepeu (interpretado por Ricardo Graça Mello).

Pepeu, aliás, é um personagem central nesse sentido: abandona uma família destruída, à busca do sonho de ser famoso; seu encontro com Valente, que the ensina a surfar e a shapear pranchas, cria a alternativa que procura para ser feliz. É o personagem que supostamente compôs e canta todo o tempo a música De repente Califórnia.

\section{Considerações finais}

Na década de 70, a sua única chance de escrever algum pensamento, levantar uma polêmica ou relatar um fato para a comunidade do surf no Brasil era na pioneira revista Brasil Surf. Trinta anos depois, além das revistas especializadas, programas em rádio e televisão, são vários os sites na internet que noticiam o surf no dia-a-dia através de textos, fotos e vídeos (BocÃo, 2006b).

Articulados com o contexto nacional e dialogando com o cenário internacional, os quatro filmes analisados neste artigo, com claras distinçōes entre si, sinalizaram e contribuíram no forjar de novas dimensões simbólicas para a sociedade brasileira na transição dos anos 70/80, na qual o surfe passou a ser uma presença mais constante em vários espaços. Tais
Aqui voltamos ao curioso aparente paradoxo do desenvolvimento do campo do surfe. A manutenção de uma visão romântica sobre o esporte vai mesmo acabar impulsionando, não sem debate, a profissionalização: era uma forma dos amantes da prática ganharem a vida sem dela se afastarem. Nesse mesmo cenário, iniciativas comerciais diversas vão se estruturar. Isso de forma alguma significa o abandono do discurso romântico: muito pelo contrário, ele é central nas estratégias de "marketing" construídas ${ }^{21}$. Aliás, os dois filmes são exemplos típicos dessa apreensão.

Essas contradiçōes serão sempre aparentes. $\mathrm{Na}$ parede da oficina de Valente se lê: "Minha prancha é meu instrumento, o surfe minha expressão". As pranchas são confeccionadas artesanalmente, mas também herdeiras do enorme desenvolvimento tecnológico e da descoberta de novos produtos, como a fibra de vidro e o poliuretano ${ }^{22}$.

Para concluir, é importante dizer que é óbvio que uma parte muito pequena dos cariocas, nem mesmo a maioria dos jovens da Zona Sul, vivia algo semelhante ao que era exibido nas telas pelos dois filmes. O que nos interessa, todavia, não é tratar as películas como expressão da realidade e sim como representaçóes que de alguma forma partiam de elementos concretos para construir modelos de juventude, pautados em perspectivas de sociedade.

E nesse cenário, um novo esporte era elencado como exemplar, uma nova prática esportiva passaria a frequentar as telas dos cinemas como sinônimo de liberdade, saúde, desafio: o surfe.

películas permitem captar um importante momento de configuração do campo constituído ao redor desta prática, tendo contribuído, junto com outras mídias, para a divulgação, para um público mais amplo, do estilo de vida e da cultura a ela relacionadas.

O surfe, o vôo livre, o "windsurf" são apresentados como uma forma de encontro de uma nova juventude saudável com a natureza, um certo contraponto à lógica do trabalho e a uma sensação de ambiente opressivo das cidades: trata-se de uma alternativa.

Por um lado, o cinema incorporou e tematizou um universo cuja adesão entre os jovens era significativa. Crianças e adolescentes constituíram grande parte do público que compareceu às salas de projeção, e muitos deles se encantaram com a nova proposta de viver 
exibida nas produçōes. Por outro, ao difundir as diversas dimensões do surfe, ajudaram não só a aumentar o número de adeptos, mas também a disseminar uma série de produtos consumidos pelos atletas e/ou admiradores (pranchas, bermudas, óculos escuros, camisetas, adesivos, bonés, mochilas etc.) e práticas como a alimentação natural, o luau, certos estilos musicais ("rock", "reggae" e mesmo um específico, o "surf music").

$\mathrm{Na}$ verdade, poucos esportes são tão cinematográficos quanto o surfe, notadamente pelo espetáculo "cênico" e pela "adrenalina" e emoção desencadeadas pelas cenas no mar. Não surpreende que na história do cinema, notadamente norteamericano, seja um dos esportes mais filmados ${ }^{23}$. Ricardo BoCÃo (2004c) vai direto ao ponto:

E não tem coisa mais legal do que ver surf de qualidade, com ondas perfeitas, projetadas numa tela enorme e com uma puta trilha sonora gravada em 5.1 dolby surround. Mais emocionante, só mesmo ao vivo e, mesmo assim, em alguns picos as ondas quebram longe $\mathrm{da}$ areia e você ainda tem que subir numa duna, longe da água, para ver a galera surfando.

No cinema brasileiro, nas décadas seguintes, o surfe continuaria a marcar presença. Vejamos uma breve lista de alguns filmes onde ele esteve, em maior ou menor grau, representado: Manobra radical (Elisa Tolomell, 1991), Surf adventures (Arthur Fontes, 2001), Fábio fabuloso (Pedro Cezar, Ricardo Bocão, Antônio Ricardo, 2004), O diabo a quatro (Alice de Andrade, 2004), 1972 (José Rondeau, 2005), Tow in surfing (Jorge Guimarães, Rosaldo Cavalcanti, 2006), Podecrer! (Arthur Fontes, 2007), Meu nome não é Johnny (Mauro Lima, 2008).

Essas películas acima, contudo, podem nos dizer outras coisas sobre a sociedade e sobre a própria prática do surfe. O próprio processo de profissionalização e aumento do número de praticantes expressa outro cenário e traz preocupaçóes para os envolvidos com o campo, algo que não poucas vezes desencadeou discursos saudosistas e o uso da história como forma de construir uma legitimidade para que alguns proponham a manutenção de certos valores. Isso fica bem denotado na posição de Ricardo BoCĀo (2003):

Agora, na primeira década do novo século, um aumento repentino de gente na água está ameaçando valores originais do surf, como a pureza, a autenticidade e o romantismo. (...). O surf, como nós o conhecemos, veio do Hawaii. E as tradiçóes havaianas do universo do surf na primeira metade do século passado, antes dos campeonatos, das revistas e de toda a comercialização de produtos, eram fruto de valores envolvidos pela pureza, autenticidade e romantismo. Aqui no Brasil estes valores foram cultuados, principalmente, na década de 60 e na primeira metade de 70. Agora, na primeira década do novo século, um aumento repentino de gente na água está ameaçando valores originais do surf, como a pureza, a autenticidade e o romantismo.

Mas essa já é outra história, assunto para outro artigo.

\begin{abstract}
Surfing in the cinema and the Brazilian society in the transition from the 70 s to the $80 \mathrm{~s}$

In the transition from the 70s to the 80sfour films in which surfing was a central issue were released, in Brazil, attracting large crowds: Nas ondas do surf, by Lívio Bruni Júnior (1978); Nos embalos de Ipanema (1978), Menino do Rio (1981), and Garota Dourada (1983), all by Antônio Calmon. Besides, this sport was represented as a side theme in other motion pictures. What lies beneath this enormous growth of surfing's presence in Brazil's movies? How can this help us think not only the different configurations of the sport field but also the specific Brazilian sociocultural context? Considering such questions, this article aims to analyse these four films, produced in Brazil between 1978 and 1983, in which surfing occupied privileged space. We conclude that the studied films signaled and helped forge the new symbolic dimensions for the Brazilian society in the transition year 70/80, in which surfing has become a more constant presence in several areas.
\end{abstract}

UNITERMS: Sport history; Sport sociology; Youth. 


\section{Notas}

1. Algumas fontes indicam que o surfe já era praticado no Brasil desde a década de 30, na cidade de Santos. Contudo, é mesmo no Rio de Janeiro da década de 50 que começa a se estruturar um campo ao redor da prática, inclusive com os primórdios de uma cultura surf. Para maiores informações, ver estudo de DiAs (2008).

2. A trajetória de Colassanti é bastante interessante. Participou, como ator ou na parte técnica, em mais de 30 longasmetragens, tendo sido também um dos pioneiros do surfe e da caça submarina no Brasil. Morador de Ipanema, era a perfeita incorporação de um personagem de filme de surfe.

3. Para maiores informações sobre a relação entre a bossa nova e o público jovem, ver estudos de Morelli (1991) e BUENO (2005). Foge ao recorte deste estudo discutir profundamente esse filme. Para maiores informaçôes, ver estudo de SALEM (1997).

4. Em consulta realizada no banco de dados da Cinemateca Brasileira (www.cinemateca.com.br) pode-se perceber uma curiosa ocorrência. Nos anos de 1966/1967 é possível encontrar cenas de surfe em cinejornais. Após esse período, somente em 1977 o esporte volta a esses programas, como, por exemplo, em Brasil Hoje, número 210, onde se podem encontrar imagens da etapa brasileira do $1^{\circ}$ Circuito Mundial de Surfe, realizada em 1976, no Arpoador, Rio de Janeiro.

5. Para maiores informaçōes, ver também o sítio da Agência Nacional de Cinema (Ancine): http://www.ancine.gov.br/

6. Maiores informações e a lista completa de filmes em que o surfe esteve presente podem ser obtidas em http:// www.anima.eefd.ufrj.br/esportearte/.

7. Para o historiador australiano Douglas Bоотн (2001), contribuiu para a divulgação da cultura do surfe o fato de os grandes estúdios cinematográficos estadunidenses, os mais poderosos do mundo, estarem sediados na Califórnia.

8. É interessante observar que algumas cenas de surfistas já tinham sido pioneiramente exibidas em Waikiki surfers, de R.K. Bonine (Thomas Edison Company, 1906).

9. Uma discussão sobre esse aspecto pode ser encontrada no estudo de BuENo (2005).

10. Ricardo Bocão foi um dos surfistas mais importantes do Brasil nos anos 70. Um dos pioneiros na estruturação do campo, apresentador e produtor de programas de televisão e de filmes, organizador das primeiras escolas de surfe e de vários serviços ligados ao esporte, hoje é um dos colunistas da Fluir. Usamos neste artigo suas falas por as considerarmos fonte privilegiada acerca das representações sobre a prática.

11. Produção: Livio Bruni Junior, Rossini Maranhão Filho; Elenco: Pepe, Rico, Daniel Friedman, Otávio, Bocão, Maracá, Zeca Proença, André Pitzalis, Gerry Lopez, Rory Russel, Mark Richards, Mark Warren, Reno Abellira, Michael Ho; Narração: Sergio Chapelin; Montagem: Leovigildo Cordeiro (Radar).

12. Vale lembrar que inicialmente o vôo livre chegou a ser chamado de "sky surf" e que Pepê, um dos pioneiros do surfe, foi também campeão mundial de asa delta.

13. Produtor: Pedro Carlos Rovai; Roteiro: Armando Costa, Leopoldo Serran, Antônio Calmon, Pedro Carlos Rovai e Silvan Paezzo; Fotografia e câmera: Roberto Pece; Intérpretes: André de Biase, Angelina Muniz, Zaira Zambelli, Paulo Villaça, Roberto Bonfim, Selma Egrei, Gracinda Freire, Yara Amaral, Suzy Arruda, Jacqueline Laurence, Mauro Mendonça, Ronaldo Santos, Stepan Nercessian, Flávio São Thiago.

14. Entrevista publicada no Globo de 13 de junho de 1978. Disponível em: http://www.guesaaudiovisual.com/palavras/ EntrevReport/AntonioCalmonAspornochanchadas.html. Acesso em 5 de janeiro de 2008.

15. Roteiro: Antônio Calmon e Bruno Barreto; Produção: Luiz Carlos Barreto e Lucy Barreto; Música: Guto Graça Mello; Fotografia: Carlos Egberto; Elenco: André de Biase, Cláudia Magno, Ricardo Graça Mello, Cissa Guimarães, Cláudia Ohana, Evandro Mesquita, Sérgio Mallandro, entre outros.

16. Roteiro: Antônio Calmon e Flávio Tambelini; Produção: Luiz Carlos Barreto e Lucy Barreto; Música: Guilherme Arantes; Fotografia: Carlos Egberto; Elenco: André de Biase, Cláudia Magno, Andréa Beltrão, Ricardo Graça Mello, Sérgio Mallandro, Roberto Bataglin, Bianca Byington, Geraldo Del Rey, Marina Lima, Fabianne Rocha, Carlos Wilson, Alexandre Frota, Ritchie, Guilherme Arantes.

17. Vale lembrar que o produtor já organizara o espetáculo "Som, Sol e Surf", por ocasião de um dos Festivais realizados em Saquarema, no ano de 1976.

18. Para maiores informações, ver as obras de DAPIEVE (1995) e BuEno (2005).

19. Para uma discussão sobre a forma de filmar de Calmon, ver o estudo de Ramos (1995).

20. É somente em 1987 que vai surgir o primeiro campeonato brasileiro profissional de surfe. De qualquer forma, como vimos, o campo já estava se delineando e se profissionalizando desde meados dos anos 70 .

21. Uma discussão interessante sobre tal aspecto pode ser encontrada no estudo de FORTES (2007). 
22. Para maiores informaçôes sobre a importância da tecnologia para o surfe, ver estudo de DiAS (2008).

23. Somente, por motivos diversos, o boxe foi tão filmado. Para maiores informações, ver estudo de Melo e VAZ (2006).

\section{Referências}

BOCÃO, R. Respeitando nossa história. Fluir, Rio de Janeiro, v.20, n.212, 2003a. Disponível em: <http://fluir.ig.com.br/ colunistas/03_02_fala.shtml>. Acesso em: 6 jan. 2008.

. Há 20 anos. Fluir, Rio de Janeiro, v.20, n.220, 2003b. Disponível em: <http://fluir.ig.com.br/colunistas/ 216_fala_bocao.shtml>. Acesso em: 6 jan.2008.

. Os meus 21 anos. Fluir, Rio de Janeiro, v.21, n.232, out./2004a. Disponível em: <http://fluir.ig.com.br/colunistas/ 228_fala_bocao.shtml>. Acesso em: 6 jan.2008.

. Memoráveis lembranças. Fluir, Rio de Janeiro, v.21, n.224, 2004b. Disponível em: <http://fluir.ig.com.br/ colunistas/220_fala_bocao.shtml>. Acesso em: 6 jan.2008.

. A magia do cinema. Fluir, Rio de Janeiro, v.21, n.233, 2004c. Disponível em: <http://fluir.ig.com.br/colunistas/ 229_fala_bocao.shtml>. Acesso em: 6 jan.2008.

Odisséia cinematográfica. Fluir, Rio de Janeiro, v.22, n.237, 2005. Disponível em: http://fluir.ig.com.br/colunistas/ 233_fala_bocao.shtml. Acesso em: 6 jan.2008.

. A verdadeira história. Fluir, Rio de Janeiro, v.23, n.249, 2006a. Disponível em: http://fluir.ig.com.br/colunistas/ 246_fala_bocao.shtml. Acesso em: 6 jan.2008.

. O começo do surf professional. Fluir, Rio de Janeiro, v.23, n.254, 2006b. Disponível em: http://fluir.ig.com.br/ colunistas/251_fala_bocao.shtml. Acesso em: 6 jan.2008.

BOOTH, D. Australian beach cultures: the history of sun, sand and surf. London: Frank Cass, 2001.

BUENO, Z.P. Leia o livro, veja o filme, compre o disco: a produção cinematográfica juvenil brasileira na década de 1980. 2005. Tese (Doutorado em Multimeios) - Instituto de Artes, Unicamp, Campinas, 2005.

CARMO, P.S. Culturas da rebeldia: a juventude em questão. São Paulo: Senac, 2001.

CLARKE, J. Subcultures, cultures and class. In: HALL, S.; JEFFERSON, T. (Eds.). Resistance through rituals: youth subcultures in post-war Britain. Hutchinson: London, 1976. p.9-75.

DAPIEVE, A. BRock: o rock brasileiro dos anos 80. Rio de Janeiro: Editora 34, 1995.

DIAS, C.A.G. Urbanidades da natureza: os esportes e a cidade do Rio de Janeiro. Rio de Janeiro: Apicuri, 2008.

DIAS, C.A.G.; MELO, V.A. A saúde da nova cidade: urbanização e lazer no Brasil (décadas de 1950/1970). Rio de Janeiro: PPGHC, 2007.

FORTES, R. Entre passado, presente e futuro: a memória nas edições comemorativas da revista Fluir. Esporte e Sociedade, Rio de Janeiro, v.2, n.6, p.1-22, 2007.

MARAÑON, C. Futbol y cine. Madrid: Ocho y Medio, 2005.

MELO, V.A. Cinema e esporte: diálogos. Rio de Janeiro: Aeroplano, 2006

MELO, V.A.; VAZ, A.F. Cinema, corpo, boxe: suas relações e a construção da masculinidade. Artcultura, Uberlândia, v.8, n.12, p.139-60, 2006

MELLO, L.A. A onda maldita: como nasceu a Fluminense FM. Niterói: Arte e Cultura, 1992.

MERIDA, P. El boxeo en el cine. Barcelona: Kaplan, 1995.

MIRA, M.C. O leitor e a banca de revistas: a segmentação da cultura no século XX. São Paulo: Olho d'Água/Fapesp, 2001. MORELLI, R. Indústria fonográfica. Campinas: Editora da Unicamp, 1991.

MORIN, E. Cultura de massas no século XX. Rio de Janeiro: Forense Universitária, 1997. v.1: Neurose.

RAMIÓ, J.R. Presencia del deporte em el cine español. Madrid: Fundación Andalucia Olímpica y Consejo Superior de Deportes, 2003.

RAMOS, J.M.O. Televisão, publicidade e cultura de massa. Petrópolis: Vozes, 1995.

ROSZAK, T. A contracultura: reflexōes sobre a sociedade tecnocrática e a oposição juvenil. Petrópolis: Vozes, 1972.

SALEM, H. Leon Hirszman: o navegador das estrelas. Rio de Janeiro: Rocco, 1997. 
MELO, V.A. \& FORTES, R.

ENDEREÇO

Victor Andrade de Melo

Praia de Botafogo, 472, apto. 810

22250-040 - Rio de Janeiro - RJ - BRASIL

e-mail: victor.a.melo@uol.com.br
Recebido para publicação: 12/09/2008

Aceito: 20/07/2009 